\title{
Optimasi Umur Pahat Pada Proses Pembubutan Baja ST 42
}

\author{
Chendri Johan $1^{1)}$, Santo2 ${ }^{2)}$ \\ 1) chendrijohan@ukitoraja.com 1, ${ }^{2)}$ Santo91@gmail.com 2
}

\begin{abstract}
Abstrak
Tingginya kecepatan potong (Vc), dan kedalaman potong (a) yang divariasikan membuat umur pahat semakin menurun. Variabel pemesinan sangat berpengaruh terhadap umur pahat yaitu kecepatan potong (Vc) yang memiliki kontribusi 13.36\%, dan kedalaman potong (a) yang memiliki kontribusi $68.56 \%$ terhadap umur pahat. Nilai korelasi antara umur pahat terhadap variabel proses pemasinan sangat signifikan, dengan nilai korelasi antar predictor diperoleh $R=0.999$.
\end{abstract}

Kata Kunci : kecepatan poton, kedalaman potong, umur pahat, pemesinan

Abstract

The high cutting speed $(V c)$ and the varying depth of cut (a) made the tool life decrease. Machining variables are very influential on the tool life, namely cutting speed (Vc) which has a contribution of $13.36 \%$, and depth of cut (a) which has a contribution of $68.56 \%$ to the tool life. The correlation value between tool life and the machining process variable is very significant, with the correlation value between the predictors obtained by $R=0.999$.

Keywords: cutting speed, depth of cut, tool life, machining

\section{PENDAHULAN}

Sebuah industri tidak lepas dari adanya proses pemesinan yang menjadi inti dari sebuah proses produksi. Peran mesin sebagai pembantu manusia tidak dapat di hindari lagi. Ketelitian geometri serta variasi produk menuntut sumber daya manusia untuk lebih berkembang. Dalam bidang perbengkelan misalnya, sudah banyak ditemukan alat-alat yang dapat meringankan pekerjaan manusia seperti mesin bubut, sekrap, freis, bor, gerinda, dan sebagainya.

Data mengenai umur pahat ini sangat diperlukan dalam perencanaan proses suatu komponen/produk. Misalnya untuk menghitung pada komponen keberapa pahat harus diganti, caranya adalah dengan menghitung waktu total yang diperlukan untuk memotong suatu produk kemudian dibandingkan dengan umur pahat yang dipakai. Contoh lain sampai batas keausan yang bagai mana dari pahat sehingga tidak mengganggu ketelitian produk yang dihasilkan, karena diketahui bahwa pahat yang mengalami keausan akan mempengaruhi ketelitian produk yang dihasilkan.

Untuk itu proses penelitian ini diharapkan dapat mengetahui pengaruh kecepatan potong, dan kedalaman potong terhadap umur pahat dan nilai korelasi antara variabel pemesinan terhadap umur pahat. Umur pahat sangat penting karena sangat mempengaruhi biaya yang digunakan dalam proses pemesinan. Kecepatan potong memiliki pengaruh yang signifikan pada umur pahat diiringi dengan gerak makan dan kedalman potong.

\section{Teori Dasar}

Bubut (Turning) adalah suatu proses pemotongan benda kerja dengan menggunakan mesin bubut dengan cara memutar benda kerja dengan menggunakan mesin kemudian benda kerja dikenakan pada pahat yang digerakkan secara translasi yang sejajar pada sumbu putar benda kerja. Gerak translasi disebut gerak umpan (feeding) dan gerak putar disebut gerak potong relative.

2.1. Elemen dasar proses bubut

Pada proses membubut proses elemen dasar dapat dihitung dengan menggunakan rumus yang dapat diturunkan dengan memperhatikan Gambar 2.1. Kondisi pemotongan dapat ditentukan sebagai berikut

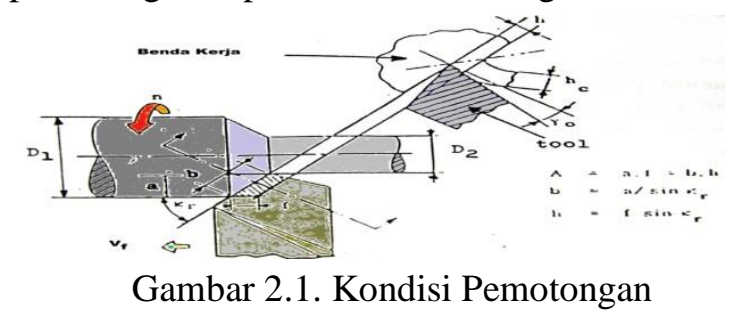


1. Dimensi-dimensi pada benda kerja $\mathrm{d}_{\mathrm{o}}=$ diameter awal benda kerja, $(\mathrm{mm})$

$\mathrm{d}_{\mathrm{m}}=$ diameter akhir benda kerja, $(\mathrm{mm})$

$l=$ panjang proses pemesinan, $(\mathrm{mm})$

$\mathrm{I}_{\mathrm{t}}=$ panjang pemotongan, $(\mathrm{mm})$

2. Dimensi-dimensi pada pahat

$\mathrm{K}_{\mathrm{r}}=$ Sudut potong utama, $\left({ }^{0}\right)$

$\mathrm{K}_{\mathrm{r}}$ = Sudut potong bantu $\left({ }^{0}\right)$

$\alpha_{\mathrm{o}}=$ Sudut bebes, $\left({ }^{0}\right)$

$\beta=$ Sudut baji, $\left({ }^{0}\right)$

$\gamma^{0}=$ Sudut geram belekang, $\left({ }^{0}\right)$

$\gamma_{\mathrm{s}}=$ Sudut geram samping, $\left({ }^{0}\right)$

3. Dimensi-dimensi pada mesin bubut

a = kedalaman pemotongan, $(\mathrm{mm})$

$\mathrm{a}=\frac{\mathrm{d} o-\mathrm{d} m}{2}$

$\mathrm{f} \quad=$ gerak makan, (mm/putaran)

$\mathrm{n}=$ putaran poros utama (putaran benda kerja) (rpm)

Dari elemen dasar pemotongan diatas dapat dihitung dengan menggunakan rumus sebagai berikut :

1. Kecepatan potong $V c=\frac{\pi \cdot d \cdot n}{1000}(\mathrm{~m} / \mathrm{menit})$..

2. Kecepatan makan $V f=f . n,(\mathrm{~mm} / \mathrm{menit})$ .........................................(2.3)

3. Waktu pemotongan $t c=\ell / V f$, (menit) ...(2.4)

4. Kecepatan pembuangan geram $: Z=A . V$.

Dimana: $\mathrm{A}=$ penampang geram sebelum

Terpotong. $A=f \cdot a,\left(\mathrm{~mm}^{2}\right)$

Sehingga: $Z=f \cdot a \cdot V$

\subsection{Umur pahat}

Umur pahat dapat didefinisikan sebagai batas keausan mata potong dengan diri diperlakukan untuk mencapai batas keausan yang telah ditetapkan. Adapun kriteria untuk melihat batas keausan yang telah ditetapkan pada proses pemesinan yang berlangsung adalah sebagai berikut :

1. Kenaikan gaya potong

2. Perubahan dimensi atau geometri pahat.

3. Terjadinya getaran/chatter

4. Penurunan kehalusan permukaan hasil pemsinan

Jadi umur pahat adalah seluruh waktu yang diperlukan untuk memotong benda kerja hingga mencapai batasan keausan.

Prosedur penentuan umur pahat dimulai dengan melakukan pembubutan terhadap benda kerja pada suatu tingkat putaran (n) kedalaman potong (a) yang divariasikan, meggunakan sebuah pahat pada geometri tertentu .
Bilamana panjang keausan pahat belum mencapai harga batas keausan, pembubutan dilanjutkan hingga panjang keausan mencapai harga batas keausan, dimana umur pahat adalah seluruh waktu pemotongan yang dipergunakan.

Untuk menghindari kerusakan fatal seperti patah pada ujung pahat, maka dalam proses pembubutan hendaknya menghindari penggunaan pahat pada kondisi yang kritis. Hal ini dapat dihindari dengan mengikuti petunjuk batas keausan kritis meurut buku (Taufiq, Rochim) dalam bukunya " Teori dan teknologi proses pemesinan bagian I" halaman 139, batas keausan kritis kusus pada pahat HSS terhadap benda kerja baja dan besi tuang batas keausa tepi $\left(\mathrm{V}_{\mathrm{B}}\right)$ adalah $0,3 \mathrm{~s} / \mathrm{d}$ 0,8 .

3. METODE

Penelitian ini menggunakan motode experimental dengan melakukan penelitian secara langsung,

\subsection{Alat dan Bahan}

1. Alat

a. Mesin bubut standar 1 unit, merek Horryson buatan Inggris.

b. Mesin asah pahat 1 unit, tipe ST 15/175 dan SNS07 merek Rema.

c. Kaliper (jangka sorong) dan mistar siku sebagai alat ukur.

d. kunci $\mathrm{T}$ untuk melonggarkan dan menguatkan pencekam.

e. Pahat center/mata bor.

f. Stopwatch.

2. Bahan

a. Material benda kerja yang digunakan ialah Baja ST 42 sebanyak 2 batang

b. Pahat bubut jenis HSS diameter $(\varnothing) 3 / 4$ inch 1 batang

\subsection{Desain Penelitian}

Desain penelitian yang digunakan adalah sesuai dengan bentuk perolehan data dalam penelitian yaitu menentukan variabel penelitian, pembentukan geometri pahat dan benda kerja.

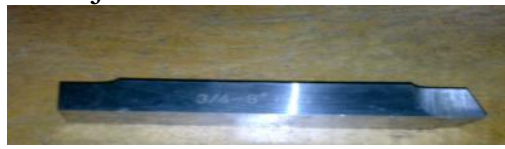

Gambar 3.1. Pahat

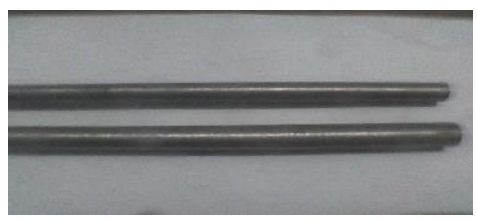

Gambar 3.2. Benda kerja

Variabel yang dimaksud adalah : 
1. Putaran (n)

Variabel benda kerja datur sesuai Putaran yang diinginkan. Putaran yang dipilih adalah 180 rpm, 260 rpm, 370 rpm, dan 540 rpm.

2. Kedalaman potong (a)

Variabel kedalaman potong (a) yang dipilih adalah $0,2 \mathrm{~mm}, 0.4 \mathrm{~mm}, 0.6 \mathrm{~mm}, 0.8 \mathrm{~mm}$.

\subsection{Prosedur Pengambilan Data}

1. Prosedur pengujian

Pada prosedur panelitian, pengambilan data keausan pahat dilakukan dengan langkahlangkah sebagai berikut :

a. Mengkalibrasi mesin bubut pada kedudukan awal/standar.

b. Memasang benda kerja pada pencekam dan kedua sisinya disenter dengan pahat senter/mata bor.

c. Memasang pahat pada dudukan pahat dengan posisi tegak lurus $\left(90^{\circ}\right)$ terhadap benda kerja.

d. Menjalankan mesin bubut.

e. Mengatur putaran spindel (n), dan kedalaman potong (a) yang dipilih.

f. Bila diameter benda kerja tidak dapat lagi dibubut maka diganti dengan benda kerja yang baru.

g. Bila pahat dinyatakan tidak dapat lagi digunakan (batas pemakaian) maka pahat tersebut dilepas dari dudukan pahat dan diganti dengan mata pahat yang baru.

h. Dimensi yang ditemukan pada pengukuran pahat marupakan dimensi untuk menentukan umur pahat.

i. Langkah 1 sampai dengan 7 diulangi sesuai kondisi permukaan yang ditentukan

\section{Model analisis}

Rujukan model yang telah berhasil dikembangkan oleh peneliti (William dan Mc Gillchrist, 1974), model yang digunakan adalah matematika yaitu respon umur pahat terhadap variasi kecepatan potong, dan kedalaman pemakanan. Model matematika tersebut digunakan dalam analisa penelitian ini dan dituliskan dalam model matematika sebagai berikut :

$$
T=K /\left(V_{c}^{m} a^{n}\right)
$$

Dimana :

$$
\begin{array}{ll}
\mathrm{T} & =\text { respon umur pahat } \\
\mathrm{K}, \mathrm{m}, \mathrm{n} & =\text { konstanta } \\
\mathrm{V}_{\mathrm{c}} & =\text { kecepatan potong } \\
\mathrm{a} & =\text { kedalaman potong }
\end{array}
$$

Persamaan diatas ditransformasikan ke dalam bentuk model logaritma, guna memudahkan untuk mengestimasi parameterparameter $\mathrm{m}$, dan $\mathrm{n}$. Persamaan menjadi :

$$
\text { ln } T=\ell n K-m \ell n V_{c}-n \ell n a
$$

Model persamaan ini, kebanyakan ditulis dalam bentuk linear sebagai berikut :

$$
Y=a_{0}+a_{1} X_{1}+a_{2} X_{2}
$$

Jika kesalahan eksperimen dinyatakan dalam notasi $\beta$ maka persamaan di atas menjadi :

$$
Y=a_{0}+a_{1} X_{1}+a_{2} X_{2+} \beta
$$

Persamaan ini merupakan persamaan polinominal derajat satu.

\section{HASIL DAN PEMBAHASAN}

1. Hasil Pengujian yang Telah Dilakukan Untuk Mengetahui Umur Pahat HSS.

Pada proses pembubutan yang telah dilakukan dengan menggunakan pahat HSS dan benda kerja ST 42 dengan variabel pemesinan yang divariasikan, hasil pengukuran umur pahat dengan menggunakan Stopwatch untuk lama proses pemesinan. Hasil pengukuran memperlihatkan bahwa: putaran benda kerja pada $180 \mathrm{rpm}, 260 \mathrm{rpm}, 370 \mathrm{rpm}$, dan $540 \mathrm{rpm}$; kedalaman potong $0.2 \mathrm{~mm}$, $0.4 \mathrm{~mm}, 0.6 \mathrm{~mm}$, dan $0.8 \mathrm{~mm}$. Maka diperoleh hasil penelitian pengukuran umur pahat, dapat diliat pada tabel berikut:

Tabel 4.1 Data Hasil Pengukuran Umur Pahat

\begin{tabular}{|c|l|l|l|}
\hline NO & $\begin{array}{c}\text { Putaran } \\
\mathrm{n}(\mathrm{rpm})\end{array}$ & $\begin{array}{c}\text { Kedalaman } \\
\text { Pemotongan } \\
\mathrm{a}(\mathrm{mm})\end{array}$ & $\begin{array}{c}\text { Umur } \\
\text { Pahat } \\
\mathrm{T}(\mathrm{mnt})\end{array}$ \\
\hline 1 & 540 & 0.8 & 15 \\
2 & 370 & 0.6 & 23 \\
3 & 260 & 0.4 & 37 \\
4 & 180 & 0.2 & 61 \\
\hline
\end{tabular}

2. Hasil perhitungan kecepatan potong $(\mathrm{Vc})$ dengan diameter benda kerja (d) $=30 \mathrm{~mm}$.

Kecepatan potong (Vc) pada proses pembubutan dapat dihitung dengan menggunakan rumus, yaitu:

$$
V c=\frac{\pi \cdot d . n}{1000},(\mathrm{~m} / \mathrm{menit})
$$

Perhitungan kecepatan potong $(\mathrm{Vc})$ dengan menggunakan rumus diatas (lampiran 4), maka diperoleh kecepatan potong $(\mathrm{Vc})$, dapat dilihat pada tabel berikut:

Tabel 4.2 Data Hasi Perhitungan Kecepatan Potong $(\mathrm{Vc})$ Dengan Diameter benda kerja (d) $=30 \mathrm{~mm}$

\begin{tabular}{|c|c|c|c|c|}
\hline $\mathrm{N}$ & $\begin{array}{c}\text { Putaran } \\
\mathrm{O}\end{array}$ & $\begin{array}{c}\text { Kedalaman } \\
\mathrm{n}(\mathrm{rpm})\end{array}$ & $\begin{array}{c}\text { Kecepatan } \\
\text { Potong } \\
\mathrm{V}(\mathrm{mm})\end{array}$ & $\begin{array}{c}\text { Umur } \\
\text { Pahat } \\
\mathrm{T} / \text { menit })\end{array}$ \\
\begin{tabular}{c|c|c|c|c|}
$\mathrm{T}$ \\
$(\mathrm{menit})$
\end{tabular} \\
\hline 1 & 540 & 0.8 & 50.868 & 15 \\
2 & 370 & 0.6 & 34.854 & 23 \\
3 & 620 & 0.4 & 24.492 & 37 \\
4 & 180 & 0.2 & 19.956 & 61 \\
\hline
\end{tabular}


a. Grafik hasil pengukuran

Dengan bantuan program Microsoft Excel hasil pengukuran umur pahat selanjutnya dapat digrafikkan terhadap variasi pemesinan, dapat dilihat pada gambar 4.1, dan 4.2, berikut:

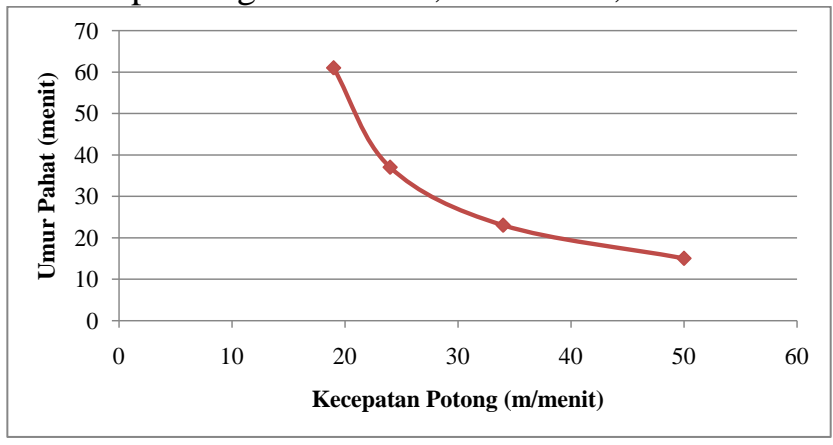

Gambar 4.1. Grafik Kecepatan Potong Terhadap Umur Pahat

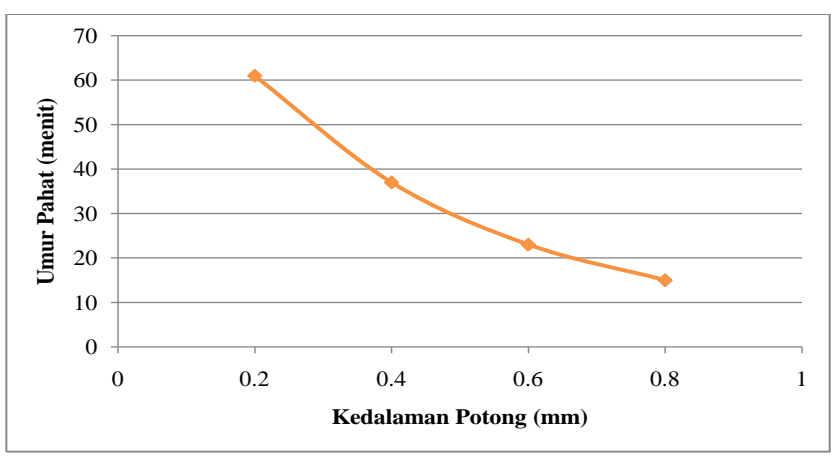

Gambar 4.2. Grafik Kedalaman Potong Terhadap Umur Pahat

\subsection{Pembahasan}

Dari gambar 4.1 dan 4.2 terlihat bahwa dengan meningkatnya kecepatan potong ( $\mathrm{Vc}$ ) dan kedalaman potong (a) maka umur pahat akan mengalami penurunan.

Umur pahat dapat ditentukan dari kecepatan potongnya. Dari gambar 4.1 terlihat bahwa semakin tinggi kecepatan potong ( $\mathrm{Vc}$ ) maka umur pahat semakin rendah dan berbanding terbalik dengan umur pahat. Dari grafik terlihat umur pahat yang paling tinggi terjadi pada kecepatan potong, rendah ( $\mathrm{Vc}=19.956 \mathrm{~m} /$ menit$)$ menghasilkan umur pahat (T) 61 menit, dan umur pahat yang paling rendah terjadi pada kecepatan potong yang paling tinggi $(\mathrm{Vc}=50.868$ $\mathrm{m} /$ menit) dengan umur pahat yang dihasilkan 15 menit.

Dari gambar 4.2 terlihat bahwa tingginya kedalaman potong (a) juga dapat mempersingkat umur pahat. Dari grafik terlihat umur pahat yang paling tinggi terjadi pada kedalaman potong, rendah $(\mathrm{a}=0.2 \mathrm{~mm})$ menghasilkan umur pahat (T) sebesar 61 menit, dan umur pahat yang paling rendah terjadi pada kedalaman potong, tertinggi $(\mathrm{a}=$ $0.8 \mathrm{~mm}$ ) dengan umur pahat yang dihasilkan 15 menit.
1. Pengaruh kecepatan potong $(\mathrm{Vc})$ terhadap umur pahat $(\mathrm{T})$

Berdasarkan gambar 4.1, terlihat bahwa hubungan antara kecepatan potong $(\mathrm{Vc})$ berbanding terbalik dengan umur pahat (T), dimana semakin tinggi kecepatan potong maka umur pahat yang dihasilkan akan semakin rendah.

Oleh kerena itu kecepatan potong (Vc) mempunyai pengaruh sebesar $13.36 \%$ terhadap umur pahat $(\mathrm{T})$ setelah dilakukan perhitungan dengan metode regresi.

2. Pengaruh kedalaman potong (a) terhadap umur pahat $(\mathrm{T})$

Berdasarkan gambar 4.2, terlihat bahwa hubungan antara kedalaman potong (a) berbanding terbalik dengan umur pahat $(\mathrm{T})$, dimana semakin tinggi kedalaman potong maka umur pahat yang dihasilkan akan semakin rendah.

Oleh karena itu kedalaman potong (a) mempunyai pengaruh sebesar $68.56 \%$ terhadap umur pahat $(\mathrm{T})$ setelah dilakukan perhitungan dengan metode regresi.

\section{KESIMPULAN}

1. Tingginya kecepatan potong $(\mathrm{Vc})$, dan kedalaman potong (a) yang divariasikan membuat umur pahat semakin menurun. Variabel pemesinan sangat berpengaruh terhadap umur pahat yaitu kecepatan potong $(\mathrm{Vc})$ yang memiliki kontribusi $13.36 \%$, dan kedalaman potong (a) yang memiliki kontribusi $68.56 \%$ terhadap umur pahat.

2. Persamaan prediksi umur pahat optimal terhadap variabel pemesinan adalah :

$$
T=\frac{1,001 \cdot a^{16,136}}{V c^{5,796}}
$$

3. Nilai korelasi antara umur pahat terhadap variabel proses pemasinan sangat signifikan, dengan nilai korelasi antar predictor diperoleh $\mathrm{R}=0.999$.

\section{DAFTAR PUSTAKA}

\section{DAFTAR PUSTAKA}

Aminy, Yusran. 2002. Optimasi Umur Pahat Pada Pembubutan Material Baja Karbon. Tesis Program Pasca Sarjana. Universitas Hasanuddin Makassar.

Bidangan, Marthen. 2004. Analisis Simpangan Pahat Pada Pembubutan Material Baja Karbon. Tesis Program Pasca Sarjana. Universitas Hasanuddin Makassar.

Bidangan, Marthen. 1991. Analisis Pengaruh Kekerasan Bahan Logam Terhadap Umur 
Pahat Pada Proses Bubut Memanjang.Tugas Sarjana. Universitas Hasanuddin Ujung Pandang.

Hendri dan Richard. Analisis Umur dan Keausan Pahat Karbida Untuk Membubut Baja Paduan (ASSAB 760) Dengan Metode Variabel Speed Macining Test. http://puslit.petra.ac.id/files/published/journ als/MES/MES070901/MES07090105.pdf, diakses pada 27 maret 2013.

Hadi Sutrisno. 1982. Analisis Regresi, Cet. V, Andi Offset. Yogyakerta.

Muin, A, Syamsir. 1989. Dasar-dasar Perancangan Perkakas Dan Mesin-mesin perkas. Rajawali Pers. Jakarta.

Rochim, Taufiq. 1985. Teknologi Proses Pemesinan I, Laboratorium Teknik Produksi dan Metrologi Industri, Jurusan Teknik Mesin, ITB. Bandung.

Rochim, Taufiq. 1993. Teori dan Teknologi Proses Permesinan, HEDS. Jakarta.

Syamsudin, R.1997. Teknik Bubut. Cet. I, Puspa Swara. Jakarta.

http://2.bp.blogspot.Com/pfmqOd3szEg/TnPIKEz glnI/AAAAAAAAAjk/TVAvohjoQkQ/s16 00/pisau+bubut+ss.jpg, diakses pada 4 Maret 2013.

http://www.scribd.com/doc/96555582/prosesbubut, diakses pada 4 Maret 2013.

http//romzneverdie.files.wordpress.com/2010/12/k lasifikasi-logam.jpg, diakses pada 22 April 2013. 